\title{
Aluminum Surface Treatment for Improved Bonding of Magnesium/ Aluminum Bi-Metallic Casting
}

\author{
Yiqing Chen ${ }^{1 *}$, Hao Zhang ${ }^{1}$, Alan Luo ${ }^{2}$, Anil.K.Sachdev ${ }^{2}$, Guangchen $\mathrm{Xu}^{1}$ and Da Chen ${ }^{1}$ \\ ${ }^{1}$ School of Materials Science and Engineering, Hefei University of Technology, Hefei, China \\ ${ }^{2}$ Chemical Sciences and Materials Systems Lab, General Motors Research \& Development Center, 30500 Mound Road, Warren, USA
}

\begin{abstract}
Magnesium/aluminum bi-metallic castings offer significant mass saving opportunities in automotive structural applications. A "zincate+galvanizing" surface treatment has been developed for aluminum alloys to provide improved wetting and metallurgical bond with molten magnesium in bi-metallic casting, due to the removal of $\mathrm{Al}_{2} \mathrm{O}_{3}$ layer and the formation of with a very thin metallic zinc film on the aluminum surfaces. The bi-metallic experiments using a selfdesigned high-vacuum test apparatus provided valuable understanding of the interfacial phenomena of Mg (AM60)/ Al (6061) bi-metallic samples. The test results show significantly improved shear strength in the bi-metallic samples with "zincate+galvanizing" surface treatment. It is recommended to adjust the pre-heating temperature and time of the aluminum substrates to control the interfacial reactions for optimum interfacial properties in the actual bi-metallic casting processes.
\end{abstract}

\section{Introduction}

Lightweight aluminum and magnesium castings offer significant mass savings compared with steel components in many automotive applications [1,2]. Hollow sections are generally more mass-effective in structural designs, and hollow castings can be made in gravity or low-pressure casting processes where sand cores are used to create very complex internal channels in the castings. A recent example is the Cadillac CTS front cradle which contains a 4-mm wall hollow aluminum casting made with a modified low pressure die casting using sand cores [3]. Short hollow sections can be made in high-pressure die casting with slides and, in limited cases, using high-strength salt cores. Another approach for introducing hollow sections in castings is "overcasting" where tubes of different materials are placed in the die cavity prior to casting the complex portions of the casting [4]. Overcasting is the key enabling technology needed for multi-materials designs where light metals $(\mathrm{Al}$ or $\mathrm{Mg}$ ) can be cast around a tube of different materials. Overcasting is also used in producing lightweight power train castings, such as the $\mathrm{BMW} \mathrm{Mg} / \mathrm{Al}$ composite engine block [5]. The composite block consists of an aluminum insert surrounded by magnesium in the upper section of the cylinder liners and watercooling jacket. The hypereutectic aluminum alloy insert avoids the use of additional liner technology and facilitates the highly loaded bolt joints for both cylinder head and crankshaft bearings. The insert also includes the water jacket, avoiding the potential problem of coolant corrosion with magnesium.

There are technical challenges in achieving strong metallurgical and mechanical bond in these bi-metallic castings due to the fact that both $\mathrm{Mg}$ and $\mathrm{Al}$ have high thermal conductivities, prone to form brittle intermetallic phases, and a large difference in thermal expansion coefficient. High Pressure Die Casting (HPDC) processes was found to be an effective process to overcast $\mathrm{Mg}$ and $\mathrm{Al}$ alloys onto steel, $\mathrm{Al}$ and Mg alloy substrates [5]. The "shrink-fit" between the cast layer and the substrate due to the large solidification shrinkage during overcasting results in a strong mechanical bond at the interface. However, no metallurgical bond was identified in the $\mathrm{Mg} / \mathrm{Al}$ interface due to the high cooling rate of HPDC process and the fact the substrate material is generally covered by an oxide layer [5].

The object of this research was to develop a surface treatment process to remove oxide film in aluminum alloy substrates and develop a low melting-point metallic zinc coating to promote metallurgical bond in the subsequent overcasting process. A high-vacuum tube furnace was designed and built to investigate the interfacial wetting and reactions between molten magnesium and the aluminum substrates. Cast magnesium alloy AM60 (Mg-6\%Al-0.3\%Mn) and wrought aluminum alloy $6061(\mathrm{Al}-1 \% \mathrm{Mg}-0.6 \% \mathrm{Si}-0.3 \% \mathrm{Cu})$ were selected to study the effects of surface treatment, contact temperature and time on the interfacial wetting and reactions between molten $\mathrm{Mg}$ and the substrates, providing important guidance in overcasting process development for such bi-metallic systems.

\section{Experimental Procedure}

\section{Materials and surface treatment}

Table 1 lists the chemical composition ranges of AM60 Mg alloy and $6061 \mathrm{Al}$ alloy used in this study. The main purpose of the surface treatment of the $\mathrm{Al}$ alloy samples was to remove the natural oxide layer from the surface and simultaneously prevent its re-formation after the treatment. The conventional zincate process refers to alkaline solutions used in a dipping (immersion) process to plate aluminum with zinc prior to electrolytic or electroless nickel plating [6]. In this study, the zincate process was modified to include a zinc-galvanizing step to replace the $\mathrm{Al}_{2} \mathrm{O}_{3}$ layer with a metallic $\mathrm{Zn}$ film of controllable-

\begin{tabular}{|c|c|c|c|c|c|c|c|c|c|}
\hline Alloy & $\mathrm{Al}$ & $\mathrm{Mg}$ & $\mathrm{Mn}$ & $\mathrm{Si}$ & $\mathrm{Cu}$ & $\mathrm{Ni}$ & $\mathrm{Fe}$ & $\mathrm{Ti}$ & $\mathrm{Cr}$ \\
\hline $\begin{array}{c}\mathrm{Mg}- \\
\text { AM60 }\end{array}$ & $5.6-6.4$ & $\mathrm{Bal}$ & $0.26-0.5$ & $\leq 0.05$ & $\leq 0.02$ & $\leq 0.001$ & $\leq 0.004$ & $\mathrm{n} / \mathrm{a}$ & $\mathrm{n} / \mathrm{a}$ \\
\hline Al-6061 & $\mathrm{Bal}$ & $0.8-1.2$ & 0.15 & $0.4-0.8$ & $0.15-0.4$ & $\mathrm{n} / \mathrm{a}$ & 0.7 & 0.15 & $\begin{array}{c}0.4- \\
0.35\end{array}$ \\
\hline
\end{tabular}

Table 1: Chemical composition ranges of the alloys studied.

*Corresponding author: Yiqing Chen, School of Materials Science and Engineering, Hefei University of Technology, Hefei, Anhui 230009, China, E-mail: xuguangchen87@126.com

Received June 14, 2012; Accepted July 23, 2012; Published July 30, 2012

Citation: Chen Y, Zhang H, Luo A, Sachdev AK, Xu G, et al. (2012) Aluminum Surface Treatment for Improved Bonding of Magnesium/Aluminum Bi-Metallic Casting. J Material Sci Eng 1:110. doi:10.4172/2169-0022.1000110

Copyright: (C) 2012 Chen Y, et al. This is an open-access article distributed unde the terms of the Creative Commons Attribution License, which permits unrestricted use, distribution, and reproduction in any medium, provided the original author and source are credited. 
thickness (several hundred nanometers). This "zincate+galvanizing" process includes the following steps: (1) degrease; (2) alkali etching; (3) pickling; (4) zincate immersion; and (5) zinc galvanizing.

\section{Bi-Metallic experiments}

Figure 1 shows a schematic illustration for high-vacuum tube furnace test apparatus designed and built in this project for bi-metallic experiments of molten magnesium on solid aluminum substrate. This apparatus consists of four subsystems, i.e., vacuum system, gas-flow control system, driving system for liquid/solid samples, and heating system. For each experiment, the quartz tube chamber was sealed and evacuated to a vacuum level of about $5 \times 10^{-3} \mathrm{~Pa}$, using a high-powered mechanical and molecular vacuum pump, and then filled with argon gas $(99.99 \%$ Ar) to a pressure of 1.2 atmosphere. A small amount of magnesium alloy ( 2.5 grams) was placed in a syringe-like quartz tube of $6 \mathrm{~mm}$ diameter, and the electric resistance furnace was heated to test temperatures of $700^{\circ} \mathrm{C}$ and $750^{\circ} \mathrm{C}$. The molten magnesium sample was then pushed out using a graphite plunger through a narrow tip of $8 \mathrm{~mm}$ diameter. The magnesium droplet prepared in this way was essentially free of oxide as any possible oxide formed during melting was broken and sheared off at the syringe tip. Just before the molten magnesium was pushed, an aluminum alloy substrate $(25 \times 15 \times 4 \mathrm{~mm})$ was pushed into the hot furnace from the other side of the tube furnace and placed beneath the outlet of the syringe. After squeezing the magnesium droplet onto the aluminum substrate for a controlled time $(70 \mathrm{sec})$, the bi-metallic sample was pulled into a room-temperature zone and cooled down for analysis.

\section{Analyses and testing}

The microstructure of the bi-metallic samples was examined using a MM6 optical microscope and a SIRION200 Scanning Electron Microscope (SEM) couple with energy dispersive spectroscopy (EDS). A SKY11-MH-3 hardness tester was used to measure the microhardness values of the $\mathrm{Mg} / \mathrm{Al}$ interfacial regions. Figure 2 shows the schematics of shear strength testing of the bi-metallic samples, using a MTS810 mechanical testing machine. Aluminum alloy 6061 samples of $25 \times 15 \times 4 \mathrm{~mm}$ were polished and drilled with a hole of $8 \mathrm{~mm}$ diameter, and molten magnesium droplet then was squeezed into the hole and solidified in various process conditions. A plunger of $7.8 \mathrm{~mm}$ diameter was lowered to push the magnesium portion (diameter $r=8$ $\mathrm{mm}$ ) of bi-metallic samples, to measure the load required to fracture the sample $\left(F_{\max }\right)$ and calculate the shear strength $\left(\Gamma_{\text {int }}\right)$ according to the following equation:

$$
\tau_{\text {int }}=\frac{F \max }{2 \pi r t}
$$

Where $t$ is the thickness of the bi-metallic sample.

\section{Results and Discussion}

\section{Temperature control}

It is important to monitor the substrate temperature vs. time at different furnace temperatures (Figure 3) during the bi-metallic experiments. Since the solidus temperature of 6061 aluminum alloy is $582^{\circ} \mathrm{C}$ [7], it is advisable not to overheat the substrate above this temperature to avoid any potential melting before the molten magnesium reaches the substrate surface. Therefore, according to (Figure 3), the substrate pre-heating time was controlled within 120 sec. and $80 \mathrm{sec}$, for test (furnace) temperatures of $700^{\circ} \mathrm{C}$ and $750^{\circ} \mathrm{C}$, respectively.

\section{Interfacial wetting and microstructure}

Figure 4 compares the interfacial wetting between AM60 and 6061 substrate without and with the "zincate+galvanizing" treatment, with a furnace temperature of $750^{\circ} \mathrm{C}$ and substrate pre-heating temperature of $560^{\circ} \mathrm{C}$. It is evident that aluminum substrate with "zincate+galvanizing" treatment (Figure $4 \mathrm{~b}$ ) shows significantly better wetting with magnesium, compared with the un-treated substrate.

Figure 5 depicts the interfacial microstructure of an AM60/6061 bimetallic sample (furnace temperature $750^{\circ} \mathrm{C}$, and substrate pre-heating temperature $560^{\circ} \mathrm{C}$ ). The optical micrograph in Figure $5 \mathrm{a}$ shows a clear $\mathrm{Mg} / \mathrm{Al}$ metallic boundary with no evidence of oxide in the interface. Further investigation using SEM coupled with EDS scans did show evidence of metallurgical reactions in the interfacial regions. Figure $5 \mathrm{~b}$, $5 c$ exhibit some dendritic branches of $\alpha-\mathrm{Al}$ in the interface. Since the substrate pre-heating temperature $\left(560^{\circ} \mathrm{C}\right)$ is $22^{\circ} \mathrm{C}$ below its reported solidus temperature, it is believed that these branches formed during the interactions between molten magnesium and solid aluminum. It is apparent that the aluminum surface was partially melted by molten magnesium in the bi-metallic experiments and re-solidified

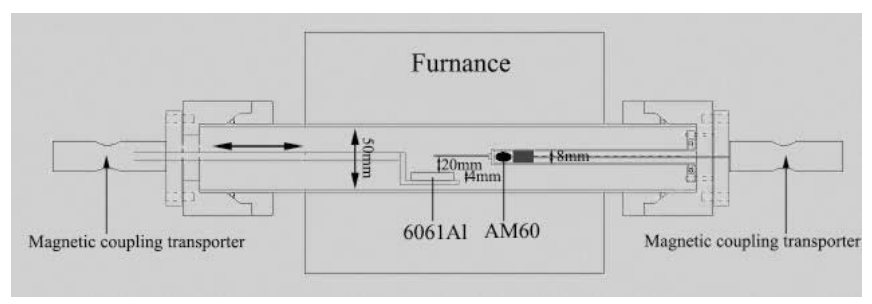

Figure 1: Schematics of high vacuum tube furnace test apparatus.

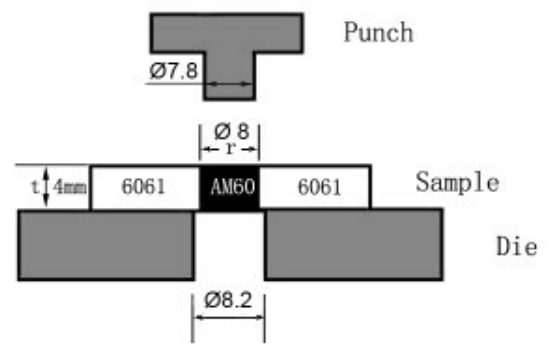

Figure 2: Shear strength test setup for bi-metallic samples (all dimensions in $\mathrm{mm})$.

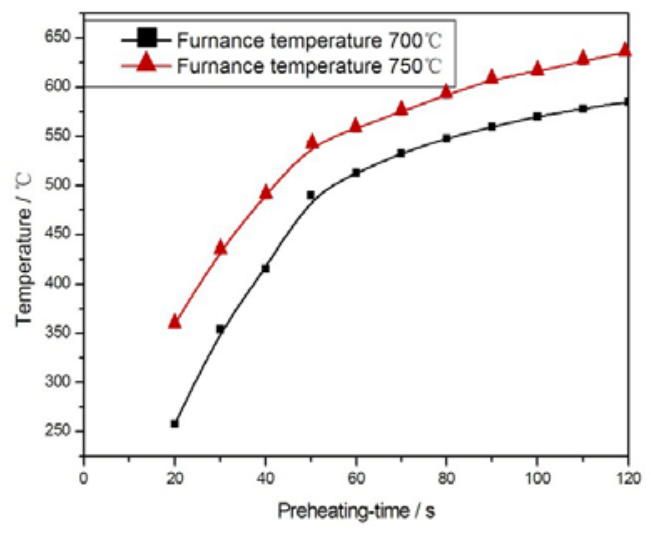

Figure 3: Substrate temperature vs. time at different furnace temperatures. 
Citation: Chen Y, Zhang H, Luo A, Sachdev AK, Xu G, et al. (2012) Aluminum Surface Treatment for Improved Bonding of Magnesium/Aluminum Bi-Metallic Casting. J Material Sci Eng 1:110. doi:10.4172/2169-0022.1000110
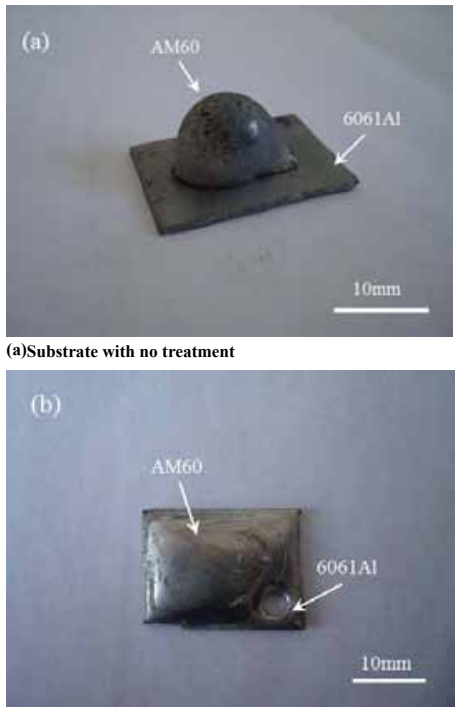

(b) Substrate with "zincate+galvanizing" treatment.

Figure 4: Interfacial wetting between AM60 magnesium alloy and 6061 aluminum substrate (a) without and, (b) with the "zincate+galvanizing" treatment. (Furnace temperature $750^{\circ} \mathrm{C}$ and substrate pre-heating temperature $\left.560^{\circ} \mathrm{C}\right)$.

during cooling, forming dendritic morphology as shown in Figure $5 \mathrm{~b}$ and $5 \mathrm{c}$. The intermetallic particles shown in Figure $5 \mathrm{~b}$ away from the $\mathrm{Mg} / \mathrm{Al}$ interface were identified as $\mathrm{Mg}_{17} \mathrm{Al}_{12}$ per EDS analysis. The element $\mathrm{Mg}$ and $\mathrm{Al}$ mapping in Figure 5d and 5e further confirm that dendritic morphology is $\alpha-\mathrm{Al}$ containing $\mathrm{Mg}$ solute. Therefore, it is feasible to control the interfacial reactions by adjusting the pre-heating temperature and time of the substrate in the actual bi-metallic casting processes.

\section{Interfacial properties}

Figure 6 plots the microhardness profile across the interfacial region of a $\mathrm{Mg} / \mathrm{Al}$ bi-metallic sample (furnace temperature $750^{\circ} \mathrm{C}$, and substrate pre-heating temperature $560^{\circ} \mathrm{C}$ ). It is obvious that the interfacial region (about $200 \mathrm{~mm}$ wide) shows significantly higher hardness values, due to increased concentrations of alloying elements and $\mathrm{Mg}_{17} \mathrm{Al}_{12}$ intermetallic particles as shown in Figure 5.

Figure 7 compares the shear strength results of $\mathrm{Mg} / \mathrm{Al}$ bi-metallic samples prepared at the furnace temperature of $750^{\circ} \mathrm{C}$, with different substrate pre-heating temperatures. It shows the shear strengths of the samples with aluminum treatment are $30-90 \%$ higher than that of untreated sample. Also, the shear strength of the treated samples increased with the increasing pre-heating temperature. When the pre-heating temperature $\left(590^{\circ} \mathrm{C}\right)$ is slightly above the temperature of the 6061 alloy, the shear strength increased significantly due to the enhanced metallurgical bond between magnesium and the substrate where more re-melting likely occurred at $582^{\circ} \mathrm{C}$.

\section{Conclusion}

1. A "zincate+galvanizing" surface treatment has been developed for aluminum alloys to provide improved wetting with molten magnesium and the aluminum substrates, due to the removal of $\mathrm{Al}_{2} \mathrm{O}_{3}$ layer and the formation of with a very thin metallic $\mathrm{Zn}$ film on the aluminum surfaces.

2. While molten magnesium AM60 alloy does not wet un-treated aluminum alloy 6061 samples, it shows excellent wettability with aluminum substrates after "zincate+galvanizing" surface treatment, in a high-vacuum bi-metallic test apparatus designed and built in this study.

3. The improved wetting between molten magnesium and treated aluminum substrate provides enhanced metallurgical bond and significantly higher shear strength in the Mg (AM60) /Al (6061) bi-metallic samples.
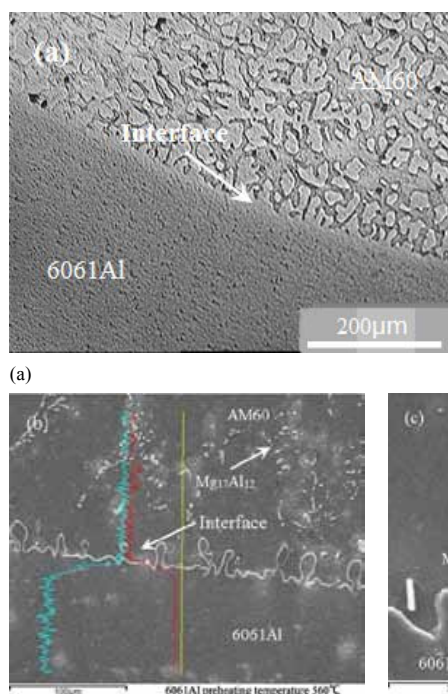

(b)
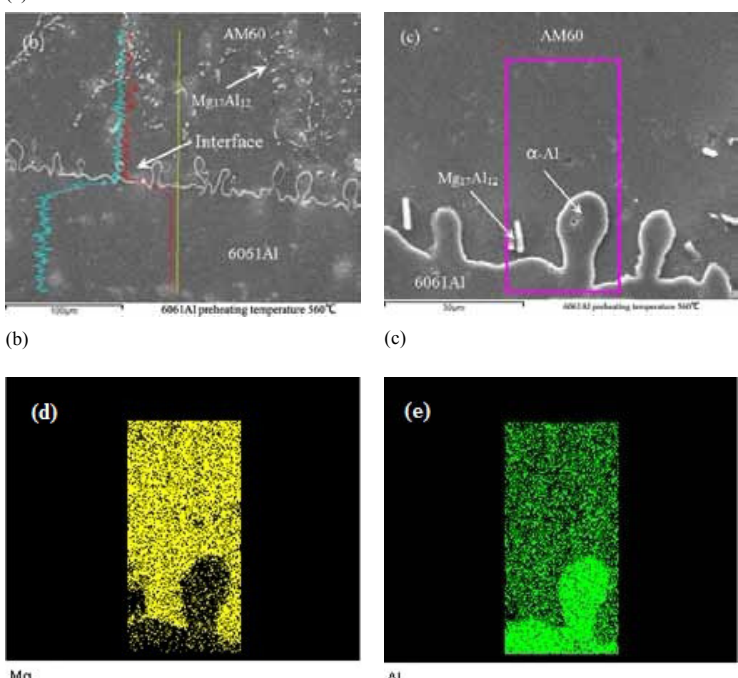

(c)

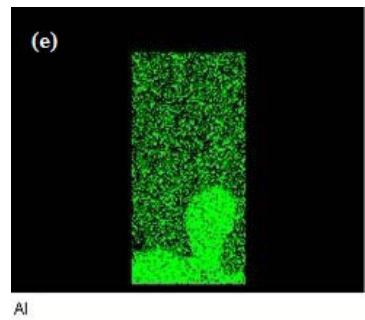

(e)

Figure 5: Interfacial microstructure of AM60/6061 bi-metallic sample (furnace temperature $750^{\circ} \mathrm{C}$, and substrate pre-heating temperature $560^{\circ} \mathrm{C}$ ): (a) optical micrograph; (b) EDS line scans; (c) SEM image; (c) Mg mapping; and (d) Al mapping.

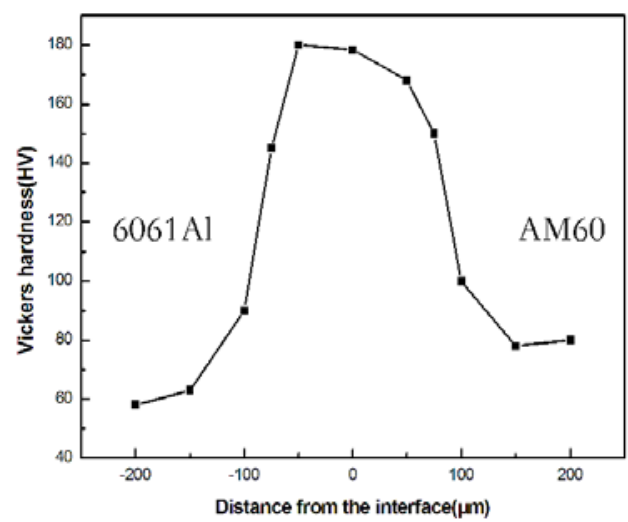

Figure 6: Microhardness measurements across an AM60/6061 interfacial region (furnace temperature $750^{\circ} \mathrm{C}$, and substrate pre-heating temperature $\left.560^{\circ} \mathrm{C}\right)$. 
Citation: Chen Y, Zhang H, Luo A, Sachdev AK, Xu G, et al. (2012) Aluminum Surface Treatment for Improved Bonding of Magnesium/Aluminum Bi-Metallic Casting. J Material Sci Eng 1:110. doi:10.4172/2169-0022.1000110

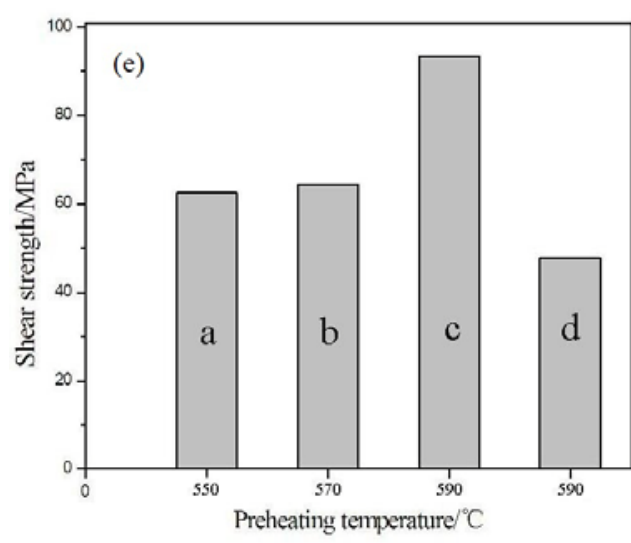

Figure 7: Interfacial shear strength of $\mathrm{Mg} / \mathrm{Al}$ bi-metallic samples (furnace temperature of $750^{\circ} \mathrm{C}$ ) of different substrate pre-heating temperatures: (a) $550^{\circ} \mathrm{C} /$ treated; (b) $570^{\circ} \mathrm{C} /$ treated; (c) $590^{\circ} \mathrm{C} /$ treated; (d) $590^{\circ} \mathrm{C} /$ untreated and (e) peak strength comparison.

4. The $\mathrm{Mg} / \mathrm{Al}$ interfacial reactions and metallurgical bond are related to the temperature and time of such interactions. It is, therefore, feasible to control the interfacial reactions by adjusting the pre-heating temperature and time of the substrate in the actual bi-metallic casting processes.

\section{Acknowledgment}

This work was carried out as a collaborative research project jointly supported by General Motors Global Research and Development Center (Warren, MI, USA) and Hefei University of Technology (Hefei, Anhui, China).

\section{References}

1. Taub AI, Krajewski PE, Luo AA, Owens JN (2007) The evolution of technology for materials processing over the last 50 years: The automotive example. JOM 59: $48-57$.

2. Luo AA (2002) Magnesium: Current and potential automotive applications JOM 54: 42-48.

3. Alan A. Luo and A.K. Sachdev (2007) Development of light metals automotive structural subsystems proceedings of the 3rd International Conference on Light Metals Technology 2007, 223-228.

4. Luo AA, Sachdev AK (2011) Process development and characterization of overcasting systems", in proceedings 115 th Metalcasting Congress. American Foundry Society 11-81.

5. Hoeschl M, Wagener W, Wolf J (2006) BMW's Magnesium-Aluminium composite crankcase, state-of-the-art light metal casting and manufacturing SAE Technical Paper 2006-01-0069.

6. Porter FC (1991) Zinc handbook. CRC Press, UK.

7. Alcoa (2012) Understanding extruded aluminum alloys - Alloy 6061 . 